\title{
Prevalence of Metabolic Syndrome in Type 2 Diabetes Mellitus Using NCEP-ATPIII, IDF and WHO Definition and Its Agreement in Gwalior Chambal Region of Central India
}

\author{
Dhananjay Yadav ${ }^{1,2}$, Sunil Mahajan ${ }^{1}$, Senthil K. Subramanian ${ }^{1}$, Prakash Singh Bisen ${ }^{1}$, Choon Hee Chung ${ }^{2}$ \& \\ GBKS Prasad ${ }^{1}$ \\ ${ }^{1}$ School of studies in Biochemistry, Jiwaji University Gwalior (Madhya Pradesh), India \\ ${ }^{2}$ Department of Internal Medicine, Yonsei University Wonju College of Medicine, Wonju, South Korea \\ Correspondence: Dhananjay Yadav, Department of Internal Medicine, Yonsei University Wonju College of \\ Medicine, Wonju, South Korea. E-mail: dhanyadav16481@gmail.com
}

Received: May 30, 2013 Accepted: August 19, 2013 Online Published: September 17, 2013

doi:10.5539/gjhs.v5n6p142 URL: http://dx.doi.org/10.5539/gjhs.v5n6p142

\begin{abstract}
The aim of study was to determine the prevalence of metabolic syndrome (MetS) in people with type 2 diabetes mellitus (T2DM). National Cholesterol Education Program (NCEP) ATPIII Criteria, International Diabetes Federation and the World Health Organization (WHO) definitions were used in quantifying the metabolic syndrome and also the concordance between these three criteria's used for identifying metabolic syndrome.
\end{abstract}

Methods: This cross-sectional study involved 700 type 2 diabetic subjects from the urban areas of Gwalior Chambal region (Central India). Subjects in the age group of 28-87 yrs were included in the study. Type I diabetics, pregnant ladies and those with chronic viral and bacterial infections and serious metabolic disorders were excluded from the study. Fasting blood glucose, Blood lipids (T-cholesterol, triglyceride, HDL-cholesterol) were assessed and anthropometry blood pressure were measured from all the subjects.

Results: The Prevalence of metabolic syndrome was found to be $45.8 \%, 57.7 \%$ and $28 \%$ following NCEP-ATPIII Criteria, IDF and WHO definitions, respectively. Using all the three definitions the prevalence was higher in women in all age groups. ATP III and IDF criteria showed good agreement ( $\kappa 0.68)$ compared to ATP III with WHO ( $\kappa 0.54)$ and IDF with WHO ( $\kappa$ 0.34) criteria. Highest prevalence was observed following IDF definition.

Conclusions: A good agreement was observed between ATPIII and IDF criteria. Maximum prevalence of Metabolic syndrome was recorded when IDF criteria was followed. NCEP-ATPIII criteria for the diagnosis of MetS and this criterion reflected equal importance to the every variable and showed a good agreement between the different criteria used.

Keywords: diabetes, metabolic syndrome, prevalence, WHO criteria, NCEP-ATPIII criteria, IDF criteria

\section{Introduction}

The metabolic syndrome is defined as a clustering of key cardiovascular risk factors, namely, abdominal obesity, dyslipidemia, hyperglycemia and hypertension in a single individual (Eckel et al., 2005). Gerald Reaven introduced the concept of the syndrome in 1988. Afterwards this constellation of cardiovascular disease (CVD) risk factors has been given a number of names, such as Syndrome X, dysmetabolic syndrome, insulin resistance syndrome and deadly quartet (Zimmet \& Alberti, 2005; Wilson et al., 1998). However, till today its' observational and epidemiological investigation has long been prevented by the absence of internationally accepted criteria for its diagnosis. To defeat this problem, in 1998, Alberti and Zimmet (1998) proposed for the first time a more unified descriptive "definition" for the diagnosis of metabolic syndrome which they called as World Health Organization (WHO) criteria. Besides, the WHO criterion has not been consistently used because of the requirement to measure serum insulin and urinary microalbumin. This problem is overcome by the Third Report of the National Cholesterol Education Program (NCEP) the Adult Treatment Panel III (ATP III) in 2001. This definition uses only simple clinical measurements of waist circumference (WC), fasting plasma glucose (PG), triglyceride (TG) and high density lipoprotein cholesterol (HDL-C) levels as well as blood pressure (BP) 
(NCEP, 2001). The ATP III criteria is more practical and found to be a better predictor of coronary heart disease (CHD) risk in the US population (Alexander et al., 2002). Unlike WHO criteria (Alberti et al., 1998) microalbuminurea is not required for ATP III criteria. Recently the ATP III definitions for MetS were renewed in which the new cut-off waist circumference for the Asia and Pacific Region and new cut-off for fasting glucose was introduced (Grundy et al., 2005). Recently, International Diabetes Federation (IDF) in 2005 proposed a new world wide definition of the metabolic syndrome (International Diabetes Federation 2005). The above three definitions are the most popular and commonly used for the diagnosis of Metabolic syndrome (Deepa et al., 2007; Clara Kelliny et al., 2008). The main focus of this definition is central obesity defined by waist circumference and has specific cut-off value for different ethnic populations as a mandatory component in MetS definition. Besides, data on the agreement between the definitions of MetS (WHO, IDF and ATP III) in T2DM population is even more diverse, which make the estimation of MetS difficult to those prognosis the T2DM for risk of cardiovascular disease. Until now, there is no specific criteria for defining MetS in type 2 diabetic population specially for India region, So we have examined MetS prevalence as stated above Gwalior-Chambal' region of India using all three well known (WHO, IDF and ATP III) definitions and also its validity by concordance between the definitions.

\section{Methodology}

A total of 700 type II diabetic subjects who were willing to take part in the study and who had given informed written consent were randomly selected and recruited from those suffering with type-2 Diabetes Mellitus. Data of 504 males and 196 females, from 28 to 87 years of age, from Gwalior were selected from January 2007 to October 2009 in a cross sectional manner. The diabetic subjects were attending the week end diabetic clinic run in the school of studies in Biochemistry at Jiwaji University Gwalior. Information about subject's age, sex, monthly income, life style, family history of diabetes and other diseases/disorders were recorded. Height, weight and waist circumferences were measured with the subject barefooted and lightly dressed. The abdominal circumference (waist) was measured at the end of expiration, by wrapping the tape at the level of the umbilicus. Body mass index (BMI) was calculated as weight in kilograms divided by the square of height in meters. Blood pressure was measured with special precaution to reduce the variation of BP value with resting values; individuals were requested to take 10 min rest at sitting position before measuring the BP. Blood pressure was measured by standardized protocols, and hypertension was defined based on the criteria of the Seventh Report of the Joint National Committee on Prevention, Detection, Evaluation, and Treatment of High Blood Pressure. According to this protocol, systolic and/or diastolic blood pressure $\geq 130 / 85 \mathrm{mmHg}$ and/or the current use of antihypertensive medication in diabetes diagnosed as hypertension. We used standard electronic B.P. measuring device. Before registering for the study written consent was obtained from each participant in respect to their willingness to take part in the study. Institutional Ethics committee at Jiwaji University Gwalior Madhya Pradesh (India) approved the study protocol. The patients assent was also taken an account before initialization of the study.

Blood sample $(3 \mathrm{ml})$ was collected from each subject. Plasma was separated by centrifuging blood at $8000 \mathrm{rpm}$ for $10 \mathrm{~min}$ and analyzed for fasting blood glucose. The blood glucose was determined by glucose oxidase-peroxidase method using a kit Monozyme India limited, Ahmadabad (Trinder, 1969). Total cholesterol, Triglyceride and HDL- Cholesterol were estimated by CHOD-PAP (Stockbridge et al., 1989), triglycerides (Fossati \& Prencipe, 1982) and HDL- Cholesterol (Lopes-virella et al., 1977) was estimated by spectrophotometric assays employing commercially available kits. LDL and VLDL were calculated from Freidewald's formula.

\subsection{Criteria for Metabolic Syndrome (WHO, NCEP-ATPIII and IDF Definition)}

The three criteria used for defining MetS are shown henceforth. The WHO definition of 1999 (Alberti et al., 1998) includes impaired glucose tolerance or diabetes and or insulin resistance. The term impaired glucose endurance i.e. impaired fasting blood tolerance; IGT $=7.8-11.0 \mathrm{mmol} / \mathrm{l}$ ) and or diabetes mellitus; $\mathrm{FBG} \geq 6.1$ $\mathrm{mmol} / \mathrm{l}$ ), was taken into account as well as two or more of the following components:

- $\quad$ Elevated arterial blood pressure $\geq 140 / 90 \mathrm{mmHg}$.

- $\quad$ Raised plasma triglyceride $(\geq 150 \mathrm{mg} / \mathrm{dl})$.

- $\quad$ Low HDL-cholesterol, $(<35 \mathrm{mg} / \mathrm{dl}$ for men and $<39 \mathrm{mg} / \mathrm{dl}$ for women).

- Central obesity (WHR: $>0.90$ for men and $>0.85$ for women) and/or BMI ( $>30 \mathrm{~kg} / \mathrm{m} 2$ ).

- Microalbuminurea (urinary albumin excretion rate $\geq 20 \mathrm{~min}$ or albumin: creatinine ratio $\geq 30 \mathrm{mg} / \mathrm{g}$ ).

Serum insulin and urine albumin excretion were not measured in our study subjects but the Proteinurea was 
measured qualitatively by sulphosalisylic acid precipitation test using repeated samples.

\subsection{NCEP, ATP III Criteria}

According to the NCEP, ATP III criteria in 2001 (National Cholesterol Education Program JAMA, 2001) for a person to be defined as having the metabolic syndrome she/he must have combination of any three or more of the following parameters: waist circumference ( $>102 \mathrm{~cm}$ for men and $>88 \mathrm{~cm}$ for women); plasma triglycerides ( $\geq 150 \mathrm{mg} / \mathrm{dl}$ ); HDL cholesterol $(<40 \mathrm{mg} / \mathrm{dl}$ for men and $<50 \mathrm{mg} / \mathrm{dl}$ for women); blood pressure $(\geq 130 / 85 \mathrm{~mm}$ $\mathrm{Hg})$, and fasting plasma glucose $(\geq 110 \mathrm{mg} / \mathrm{dl})$ were classified MetS group.

\subsection{New IDF Criteria}

According to the IDF definition in 2005 (International Diabetes Federation: The IDF consensus worldwide definition of the metabolic syndrome, 2005) for a person to be defined as having the metabolic syndrome she/he must have central obesity with ethnicity specific values for different groups. We used WC $\geq 90 \mathrm{~cm}$ in men or $\geq 80$ $\mathrm{cm}$ in women which is recommended for South Asians (Chobanian et al., 2003) plus any two or more of the following four factors:

- $\quad$ Raised TG levels $\geq 150 \mathrm{mg} / \mathrm{dl}$ ( $1.7 \mathrm{mmol} / \mathrm{l})$, or specific treatment for this lipid abnormality;

- Reduced HDL-cholesterol $<40 \mathrm{mg} / \mathrm{dl}(1.03 \mathrm{mmol} / \mathrm{l})$ in males and $<50 \mathrm{mg} / \mathrm{dl}(1.29 \mathrm{mmol} / \mathrm{l})$ in females, or specific treatment for this lipid abnormality;

- $\quad$ Raised blood pressure: systolic $\mathrm{BP} \geq 130$ or diastolic $\mathrm{BP} \geq 85 \mathrm{mmHg}$ or treatment of previously diagnosed hypertension; and

- $\quad$ Raised fasting blood glucose $\geq 100 \mathrm{mg} / \mathrm{dl}$ ( $\geq 5.6 \mathrm{mmol} / \mathrm{l}$ ) or previously diagnosed diabetes.

The prevalence of MetS using the above criteria was expressed in percentages. Student $t$ test was used for mean of the two groups viz metabolic and non metabolic syndrome group. Kappa $(\kappa)$ statistics was used for finding the agreement between the three definitions. Stepwise binary logistic regression model is used to test the associations between baseline variable and the Metabolic syndrome. For computation of data, software application programs like Microsoft Excel, Sigma Stat, Sigma Direct, and also for logistic regression SPSS trail version were used. The values were tested for significance at $\mathrm{P}<0.001, \mathrm{P}<0.05$.

\section{Results}

\subsection{Characteristics' of study population}

A total of 700 type 2 diabetic participant were recruited, with $(n=504)$ male and $(n=196)$ female. Table 1 is showing the different clinical parameters among male and female group of subject. The mean age of the participant was 54 years and the mean duration of diabetes was 5.6 years with $(\mathrm{P} \leq 0.05)$ significant difference between male and female. When comparison was made between male and female, fasting blood glucose, weight, height, BMI, systolic as well as diastolic blood pressure, pulse, cholesterol were observed to be significant $(\mathrm{P}<0.001)$. 
Table 1. Demographic, anthropometric and biochemical variables of study population

\begin{tabular}{llll}
\hline Group & Male (504) & Female (196) & Difference (95\% CI) \\
\hline Age (years) & $55 \pm 9.5$ & $53 \pm 10$ & $2(.406,3.5) *$ \\
Duration of Disease (years) & $6 \pm 5$ & $5.2 \pm 4$ & $0.8(.0163,1.58) *$ \\
Fasting (mg/dl) & $139.8 \pm 57$ & $157.8 \pm 65.8$ & $-18(-27.8,-8.15) * *$ \\
P.P (mg/dl) & $207 \pm 83$ & $219 \pm 89.3$ & $-12(-26.01,2.017)$ \\
Waist Cir. (Inches) & $38.4 \pm 19.4$ & $36.8 \pm 21.1$ & $1.6(-1.687,4.887)$ \\
Weight (kg) & $67.6 \pm 11.6$ & $61 \pm 11.2$ & $6.6(4.7,8.4) * *$ \\
Height (cm) & $165.3 \pm 8.7$ & $153.6 \pm 7.6$ & $11.7(10.3,13.09) * *$ \\
BMI (Kg/m $\left.{ }^{2}\right)$ & $24.7 \pm 4$ & $25.9 \pm 4.5$ & $-1.2(-1.8,5.15) * *$ \\
Systolic pressure (mmHg) & $132.7 \pm 20$ & $127.2 \pm 18.5$ & $5.5(2.2,8.7) * *$ \\
Diastolic pressure (mmHg) & $76.7 \pm 10.5$ & $74.2 \pm 10$ & $2.5(.78,4.2) *$ \\
Pulse rate (/min.) & $87.6 \pm 11.7$ & $92 \pm 12.1$ & $-4.4(-6.3,2.4) * *$ \\
Cholesterol (mg/dl) & $155.3 \pm 50.7$ & $169.3 \pm 50.4$ & $-14(-22.3,-5.6) * *$ \\
Triglyceride (mg/dl) & $134.5 \pm 85.3$ & $138.8 \pm 61.3$ & $-4.3(-17.4,8.8)$ \\
HDL-C (mg/dl) & $48.7 \pm 21.9$ & $49.8 \pm 19.2$ & $-1.1(-4.6,2.4)$ \\
VLDL(mg/dl) & $26.4 \pm 14.4$ & $27.7 \pm 12.2$ & $-1.3(-3.584,0.984)$ \\
LDL(mg/dl) & $90 \pm 47.4$ & $98.7 \pm 45$ & $-8.7(-16.4,-0.97) *$ \\
T.C/HDL-C (R.R) & $3.7 \pm 2.05$ & $3.8 \pm 1.8$ & $-0.1(-.428, .228)$ \\
\hline
\end{tabular}

Data expressed as Mean $\pm \mathrm{SD},{ }^{*} P<.05$, ${ }^{* *} P<.001$. Difference is the difference in the mean or percentage of the variable between males and females

Metabolic syndrome was diagnosed in 321 (45.8\%) [95\%CI: 42.31-49.69], 404 (57.7\%) [95\%CI: 54.05-61.37], 196 (28\%) [95\%CI: 24.67-31.33] participants using the NCEP-ATPIII, IDF and WHO criteria respectively (Figure 1). The prevalence of MetS among male and female were (41\% vs $58.1 \%),(52.7 \%$ vs $70.4 \%)$, (26\% vs $30 \%$ ) for NCEP, IDF and WHO criteria respectively. Prevalence of metabolic syndrome by different criteria in different Age group of subjects is depicted in Figure 2. The prevalence of metabolic syndrome was found to be highest in age group of 50-59 years with $38 \%, 38 \%, 40 \%$ based on criteria ATP III, IDF and WHO. It was also observed from figure that (60-69) years and (40-49) years have almost same prevalence of metabolic syndrome. Lowest prevalence was observed in age group of (30-39) years of $(5 \%, 4 \%, 4 \%)$ by employing the respective definitions.

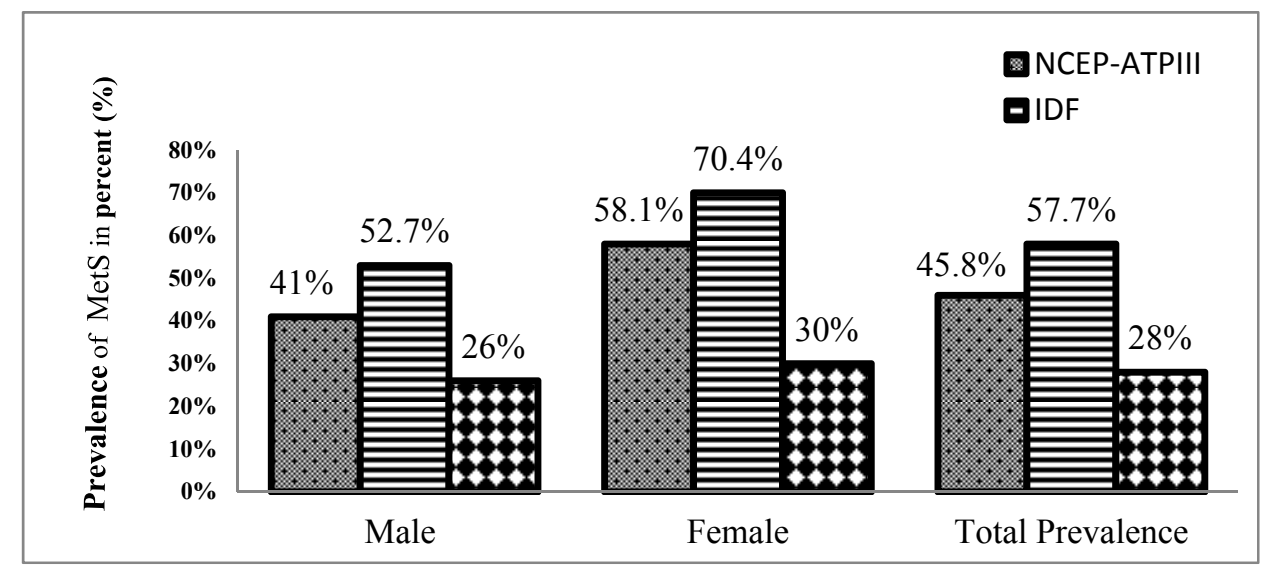

Figure 1. The prevalence of metabolic syndrome among type II diabetes mellitus using NCEP-ATPIII, IDF and WHO criteria 


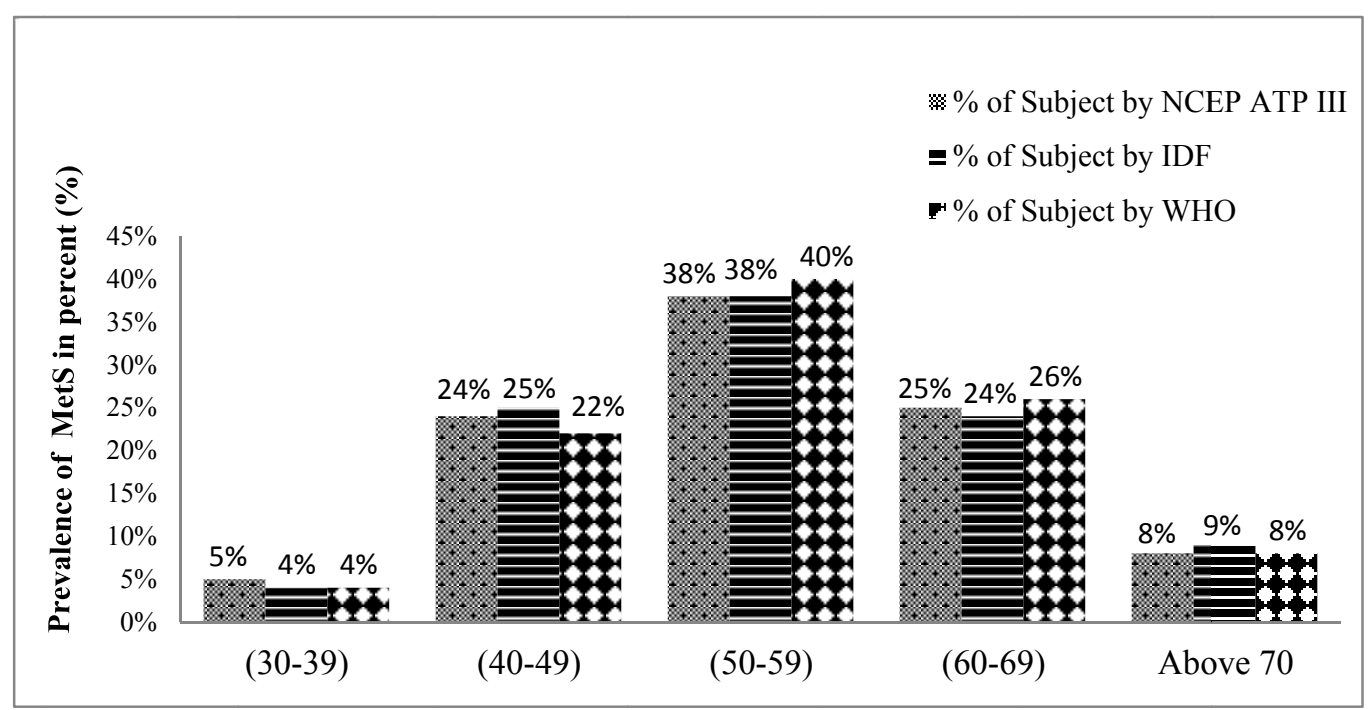

Figure 2. Metabolic syndrome in different age group of subjects

\subsection{Agreement between the NCEP-ATP III, IDF and WHO Criteria and Venn diagram}

The agreement between three definitions of metabolic syndrome was depicted in Table 2. The participants who were classified as having metabolic syndrome by NCEP-ATP III criteria, 95\% also met the criteria of IDF. However, 24.5\% (99/404) of the subjects identified as positive following IDF classification were not found to have the condition according to NCEP criteria. Good agreement was observed between ATP III and IDF criteria $(\mathrm{k}=0.680)$. Lowest agreement was observed between IDF and WHO criterions for MetS. Of the total participants having metabolic syndrome by IDF criteria, only $43.8 \%$ (177 out of 404) met the criteria of WHO.

Table 2. Agreement between the NCEP-ATP III, IDF AND WHO Criteria in diagnosing metabolic syndrome

\begin{tabular}{|c|c|c|c|c|c|}
\hline \multirow{6}{*}{ IDF } & \multirow{4}{*}{$\begin{array}{l}\text { Metabolic syndrome } \\
\text { Present }\end{array}$} & \multirow{4}{*}{$\begin{array}{l}\text { Present } \\
305\end{array}$} & \multirow{2}{*}{\multicolumn{2}{|c|}{$\begin{array}{l}\text { NCEP ATP III Criteria } \\
\text { Metabolic syndrome }\end{array}$}} & \multirow{3}{*}{$\begin{array}{l}\text { Kappa } \\
0.68\end{array}$} \\
\hline & & & & & \\
\hline & & & \multirow{2}{*}{$\begin{array}{l}\text { Absent } \\
99\end{array}$} & \multirow{2}{*}{$\begin{array}{l}\text { Total } \\
404\end{array}$} & \\
\hline & & & & & $95 \% \mathrm{CI}=(.60-.74)$ \\
\hline & Absent & 16 & 280 & \multicolumn{2}{|l|}{296} \\
\hline & Total & 321 & 379 & \multicolumn{2}{|l|}{700} \\
\hline & & & WHO & & Kappa \\
\hline & & & Metab & & \\
\hline \multirow[t]{6}{*}{ IDF } & Metabolic syndrome & Present & Absent & Total & 0.34 \\
\hline & Present & 177 & 227 & 404 & $95 \% \mathrm{CI}=(0.28-0.40)$ \\
\hline & Absent & 19 & 277 & 296 & \\
\hline & Total & 196 & 504 & 700 & \\
\hline & & & \multicolumn{2}{|c|}{ NCEP ATP III Criteria } & Kappa \\
\hline & & & \multicolumn{2}{|c|}{ Metabolic syndrome } & \\
\hline \multirow[t]{4}{*}{ WHO } & Metabolic syndrome & Present & Absent & Total & 0.54 \\
\hline & Present & 182 & 14 & 196 & $95 \% \mathrm{CI}=(.47-.61)$ \\
\hline & Absent & 139 & 365 & 504 & \\
\hline & Total & 321 & 379 & 700 & \\
\hline
\end{tabular}

In contrast, the subjects without the metabolic syndrome according to the IDF criteria, $9.6 \%$ were positive following the WHO criteria $(\mathrm{k}=0.34)$. This may have been due to the WHO definition of MetS which do not include any subjects without impaired glucose regulation. In those subjects who were classified as having the metabolic syndrome according to WHO criteria, $92.8 \%$ satisfied the ATP III criteria. Conversely the participants 
without the syndrome according to the WHO criteria $27.5 \%$ met the criteria of ATP III. The agreement between WHO and ATP III is moderate $(\mathrm{k}=0.54)$ but higher than the observed agreement between WHO and IDF criteria.

Venn diagram has been shown in Figure 3 to verify the agreement result. Here also the number of subjects with MetS in NCEP-ATPIII \& IDF was 305 whereas by NCEP-ATPIII and WHO criteria the number with MetS is 182. The number of subjects overlapped between IDF and WHO criteria was 177 . The minimum number of overlapped metabolic syndrome subject was found in IDF and WHO criterion.

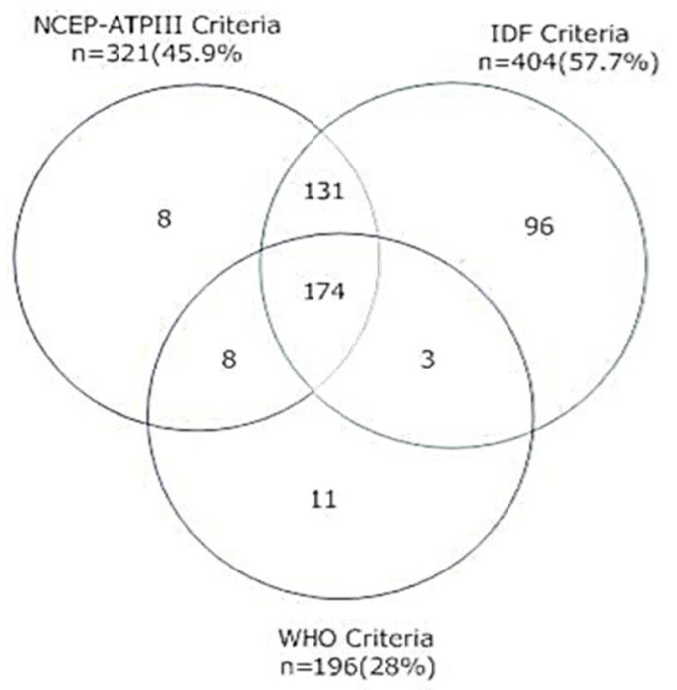

Venn diagram showing the overlapping of subjects with metabolic syndrome based on three definitions

Figure 3. Venn diagram showing the overlapping of subjects with metabolic syndrome based on three definitions

\subsection{Distribution of Clinical Data among Metabolic and Non Metabolic Groups of Type 2 Diabetes Classified according to NCEP ATP III, IDF \& WHO Criteria}

According to NCEP criteria the clinical data among two groups MetS and Non MetS of type 2 diabetes is given in Table 3. Taking together male and female, waist circumference, blood pressure (systolic as well as diastolic pressure), triglyceride \& HDL-C were found to be Significant $(\mathrm{P} \leq 0.001)$ in metabolic syndrome group compared with non metabolic syndrome. The age group in male as well as in female was not found to be significant when classified with NCEP definition. The table could also observe an association of MetS with type 2 diabetes characterized by significant elevated level of triglyceride, central obesity, fasting blood glucose etc.

Table 3. Comparison of clinical data among two groups (Metabolic and Non Metabolic) of type 2 diabetic subjects according to NCEP Criteria

\begin{tabular}{lllll}
\hline & & $\begin{array}{l}\text { Subjects with } \\
\text { Metabolic Syndrome }\end{array}$ & $\begin{array}{l}\text { Subjects without } \\
\text { Metabolic Syndrome }\end{array}$ & Significance \\
\hline Male & $\mathrm{N}$ & 207 & 297 & \\
& Age (year) & $55.7 \pm 8.8$ & $54.2 \pm 9.9$ & $\mathrm{P}=.098$ \\
Waist Circumference (Inches) & $37.8 \pm 3.2$ & $35.7 \pm 3.4$ & $\mathrm{P}=<0.001^{*} *$ \\
SBP (mmHg) & $142.6 \pm 14.7$ & $126.5 \pm 20.9$ & $\mathrm{P}=<0.001 * *$ \\
DBP (mmHg) & $82.2 \pm 10.4$ & $73.2 \pm 9.7$ & $\mathrm{P}=<0.001 * *$ \\
Duration of disease (year) & $6.1 \pm 5$ & $5.7 \pm 5.4$ & $\mathrm{P}=.841$ \\
Triglyceride (mg/dl) & $159.6 \pm 77.6$ & $114.9 \pm 56$ & $\mathrm{P}=<0.001 * *$ \\
HDL-C (mg/dl) & $42.6 \pm 19.6$ & $52.8 \pm 21.7$ & $\mathrm{P}=<0.001 * *$ \\
Fasting (mg/dl) & $151.3 \pm 48.6$ & $134 \pm 60.8$ & $\mathrm{P}=<0.001 * *$ \\
\hline
\end{tabular}




\begin{tabular}{lllll}
\hline & & $\begin{array}{l}\text { Subjects with } \\
\text { Metabolic Syndrome }\end{array}$ & $\begin{array}{l}\text { Subjects without } \\
\text { Metabolic Syndrome }\end{array}$ & Significance \\
\hline Female & $\mathrm{N}$ & 114 & 82 & \\
& Age (year) & $52.8 \pm 8.9$ & $53.4 \pm 10.3$ & $\mathrm{P}=.664$ \\
& Waist Circumference (Inches) & $39.5 \pm 4.44$ & $33.1 \pm 3.3$ & $\mathrm{P}=<0.001 * *$ \\
SBP (mmHg) & $134.2 \pm 14$ & $118.5 \pm 15.4$ & $\mathrm{P}=<0.001^{*} *$ \\
DBP (mmHg) & $77.3 \pm 10$ & $70.3 \pm 7.3$ & $\mathrm{P}=<0.001 * *$ \\
Duration of disease (year) & $6 \pm 5.6$ & $4.6 \pm 3.6$ & $\mathrm{P}=.009 *$ \\
Triglyceride (mg/dl) & $158 \pm 60.6$ & $119.8 \pm 54.1$ & $\mathrm{P}=<0.001 * *$ \\
HDL-C (mg/dl) & $45.3 \pm 17.1$ & $56.4 \pm 20$ & $\mathrm{P}=<0.001 * *$ \\
Fasting (mg/dl) & $163.9 \pm 58.9$ & $149.8 \pm 74.3$ & $\mathrm{P}=.045 *$ \\
\hline
\end{tabular}

BMI: Body mass index (kg/m²) SBP: Systolic Blood Pressure (mmHg) DBP: Diastolic Blood Pressure (mmHg) HDL-C:High density Lipoprotein cholesterol

Data were expressed as mean \pm standard deviation. Student $\mathrm{t}$ test was used for mean of the two groups. Levels of significance were represented in the form of $\mathrm{P}<0.001(* *), \mathrm{P}<0.05\left(^{*}\right)$ when compared with non metabolic syndrome subjects.

Differences in proportion of positive criteria in MetS with type 2 diabetes diagnosed by NCEP,IDF \& WHO criteria are shown in Figure 4 (4A showing NCEP definition,4B showing IDF \& 4C showing WHO criteria). The pie chart is showing differences in the proportion of positive criteria in all three respective definitions. Interestingly, we showed highest percentage of proportion in 3 criteria group was in WHO, leads to the lower combination of glucose parameter which is the mandatory variable in this definition. The three criteria group is showing more prevalent than combination of 4 or 5 criteria. Almost half of the percent of the 3 criteria recorded in combination of 4 criteria group. As the metabolic syndrome parameters are more closely interacted with each other. Blood pressure, triglyceride and HDL-C were commonly viewed in this combination (data not shown)
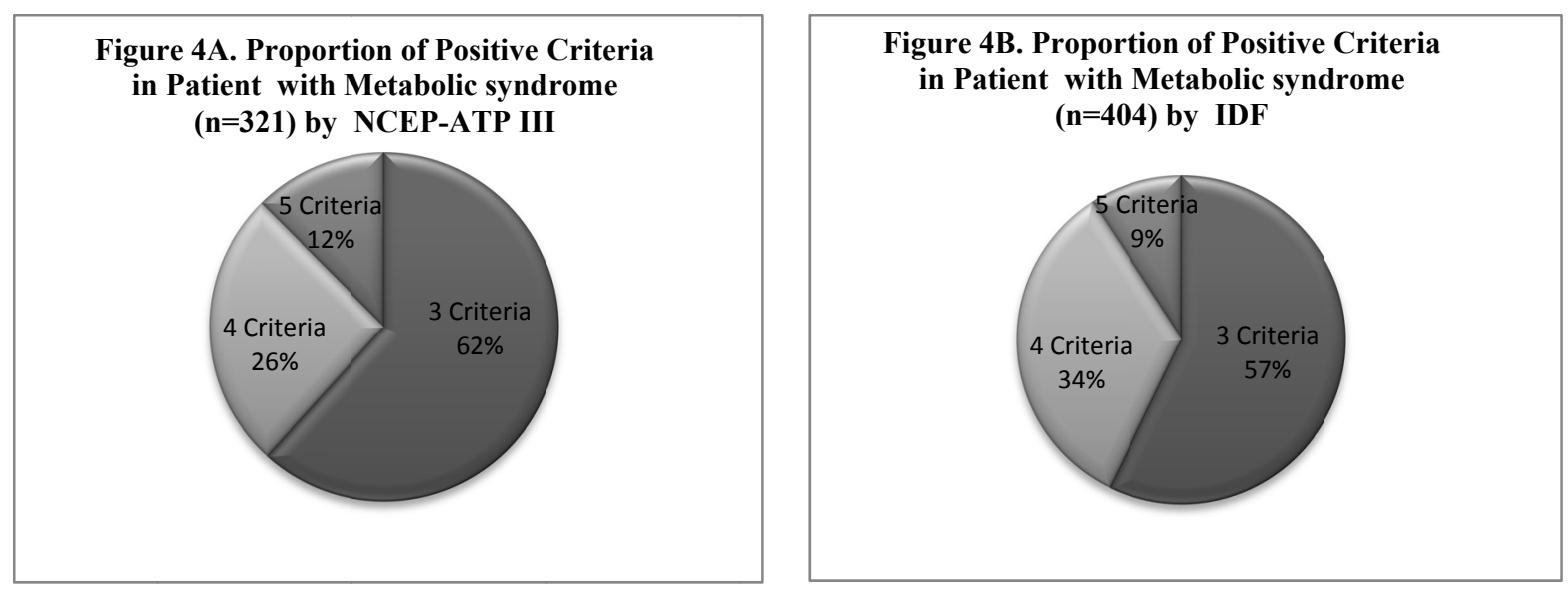


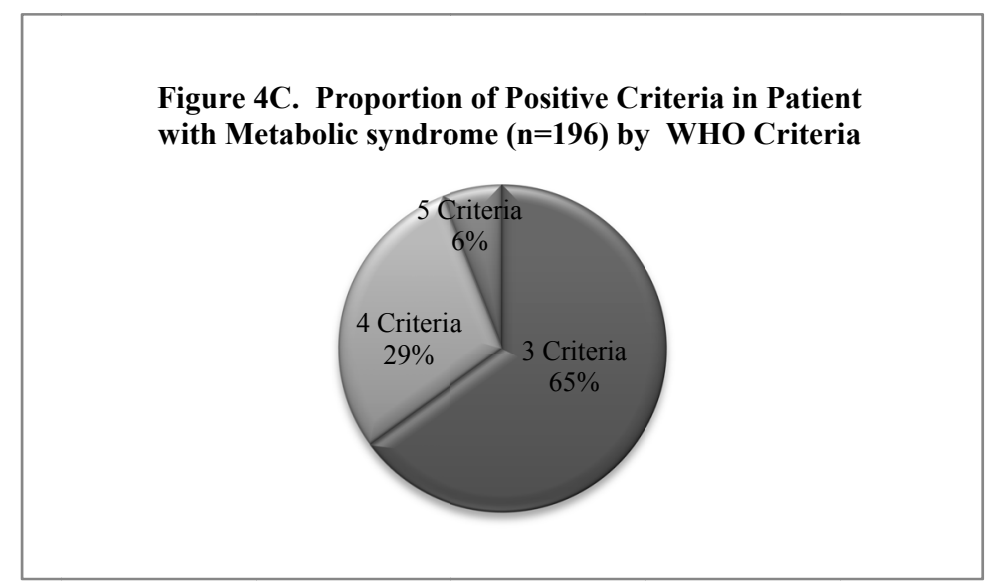

Figure 4. Different proportions of positive criteria in MetS subjects using NCEP-ATPIII, IDF \& WHO criteria

The comparison of anthropometric characteristics and metabolic variables of groups for MetS according to IDF and WHO criteria are shown in Table $4 \& 5$. The table was grouped as above mentioned, the IDF criteria showed 404 participants were having MetS while 196 subjects were positive by WHO criteria. In males, the waist circumference, blood pressure, triglyceride, HDL-C level were found to be more significant $(\mathrm{P} \leq 0.001)$ in both diagnostic criterion except the age and fasting glucose showed a non significant statistical analysis while applying to the WHO criteria. The WHO criteria is more strict on the glucose level (mandatory) in individuals before adding to another variable in the definition. In spite of that the study did not show a significant value while comparing with definition of IDF, waist circumference is the obligatory variable in diagnosing MetS. The study observed more influence of waist circumference in identifying elevated level MetS by this criterion regardless to the fasting blood glucose level in WHO criteria. In females, metabolic syndrome classified by IDF and WHO criteria establish as similar appearance or showing alike distribution of variable between the two groups except age and fasting glucose level but had showed glucose to be significant $(\mathrm{P} \leq 0.05)$ identified in IDF criteria.

Table 4. Comparison of clinical data among two groups (Metabolic and Non Metabolic) of type 2 diabetic subjects according to IDF Criteria

\begin{tabular}{lllll}
\hline & & $\begin{array}{l}\text { Subjects with } \\
\text { Metabolic Syndrome }\end{array}$ & $\begin{array}{l}\text { Subjects without } \\
\text { Metabolic Syndrome }\end{array}$ & Significance \\
\hline Male & $\mathrm{N}$ & 266 & 238 & $\mathrm{P}=.024^{*}$ \\
& Age (year) & $55.8 \pm 8.9$ & $53.9 \pm 10$ & $\mathrm{P}=<0.001 * *$ \\
& Waist Circumference (Inches) & $38 \pm 3.1$ & $34.7 \pm 3.6$ & $\mathrm{P}=<0.001 * *$ \\
& SBP (mmHg) & $139 \pm 19$ & $125.5 \pm 18.6$ & $\mathrm{P}=<0.001 * *$ \\
DBP (mmHg) & $79.5 \pm 9.7$ & $73.5 \pm 10.5$ & $\mathrm{P}=<0.001 * *$ \\
Triglyceride (mg/dl) & $150 \pm 77$ & $112 \pm 56$ & $\mathrm{P}=<0.001 * *$ \\
HDL-C (mg/dl) & $44 \pm 20$ & $54 \pm 21$ & $\mathrm{P}=<0.001 * *$ \\
\hline Fasting (mg/dl) & $150 \pm 51$ & $130 \pm 62$ & $\mathrm{P}=.226$ \\
Nemale & 138 & 58 & $\mathrm{P}=<0.001 * *$ \\
Age (year) & $52.5 \pm 9.6$ & $54.4 \pm 10.9$ & $\mathrm{P}=<0.001 * *$ \\
Waist Circumference (Inches) & $36.3 \pm 3.8$ & $33 \pm 4$ & $\mathrm{P}=<0.001 * *$ \\
SBP (mmHg) & $132 \pm 17.7$ & $69.9 \pm 8.02$ & $\mathrm{P}=<0.001 * *$ \\
DBP (mmHg) & $75.9 \pm 10.3$ & $115 \pm 53$ & $\mathrm{P}=<0.001 * *$ \\
Triglyceride (mg/dl) & $149 \pm 62$ & $59 \pm 21$ & $\mathrm{P}=.008 *$ \\
HDL-C (mg/dl) & $46 \pm 17$ & $139 \pm 77$ & $166 \pm 59$ & \\
Fasting (mg/dl) & &
\end{tabular}

Data were expressed as mean \pm standard deviation. Student $t$ test was used for mean of the two groups. Levels of significance were represented in the form of $\mathrm{P}<0.001(* *), \mathrm{P}<0.05\left(^{*}\right)$ when compared with non metabolic syndrome subjects. 
Table 5. Comparison of clinical data among two groups (Metabolic and Non Metabolic) of type 2 diabetic subjects according to WHO Criteria

\begin{tabular}{|c|c|c|c|c|}
\hline & & $\begin{array}{l}\text { Subjects with Metabolic } \\
\text { Syndrome }\end{array}$ & $\begin{array}{l}\text { Subjects without Metabolic } \\
\text { Syndrome }\end{array}$ & Significance \\
\hline \multirow[t]{8}{*}{ Male } & $\mathrm{N}$ & 135 & 369 & \\
\hline & Age (year) & $54.8 \pm 9.3$ & $54.3 \pm 9.2$ & $\mathrm{P}=.590$ \\
\hline & BMI (kg/m2) & $26.6 \pm 3.6$ & $24.1 \pm 3.5$ & $\mathrm{P}=<0.001 * *$ \\
\hline & $\mathrm{SBP}(\mathrm{mmHg})$ & $146.7 \pm 19.1$ & $127.5 \pm 19.3$ & $\mathrm{P}=<0.001 * *$ \\
\hline & $\mathrm{DBP}(\mathrm{mmHg})$ & $83.9 \pm 10$ & $74 \pm 10.1$ & $\mathrm{P}=<0.001 * *$ \\
\hline & Triglyceride (mg/dl) & $168.5 \pm 11.8$ & $123 \pm 54.8$ & $\mathrm{P}=<0.001 * *$ \\
\hline & HDL-C (mg/dl) & $41.4 \pm 23$ & $52.1 \pm 25.7$ & $\mathrm{P}=<0.001 * *$ \\
\hline & Fasting $(\mathrm{mg} / \mathrm{dl})$ & $147.4 \pm 52$ & $139 \pm 52$ & $\mathrm{P}=0.109$ \\
\hline \multirow[t]{8}{*}{ Female } & $\mathrm{N}$ & 61 & 135 & \\
\hline & Age (year) & $53.8 \pm 8.2$ & $53.2 \pm 9.6$ & $\mathrm{P}=.673$ \\
\hline & BMI $(\mathrm{kg} / \mathrm{m} 2)$ & $27.1 \pm 4.9$ & $25 \pm 4.3$ & $\mathrm{P}=0.003^{*}$ \\
\hline & $\mathrm{SBP}(\mathrm{mmHg})$ & $138 \pm 20.1$ & $127.3 \pm 16$ & $\mathrm{P}=<0.001 * *$ \\
\hline & $\mathrm{DBP}(\mathrm{mmHg})$ & $79 \pm 10.8$ & $74 \pm 9.6$ & $\mathrm{P}=<0.001 * *$ \\
\hline & Triglyceride (mg/dl) & $174.2 \pm 66$ & $137.2 \pm 64.9$ & $\mathrm{P}=<0.001 * *$ \\
\hline & HDL-C (mg/dl) & $39.5 \pm 15.7$ & $50 \pm 22.5$ & $\mathrm{P}=0.001 * *$ \\
\hline & Fasting (mg/dl) & $166.9 \pm 61$ & $157.2 \pm 70$ & $\mathrm{P}=0.352$ \\
\hline
\end{tabular}

Data were expressed as mean \pm standard deviation. Student $t$ test was used for mean of the two groups. Levels of significance were represented in the form of $\mathrm{P}<0.001\left({ }^{* *}\right), \mathrm{P}<0.05\left(^{*}\right)$ when compared with non metabolic syndrome subjects.

\subsection{Prevalence of Metabolic Syndrome for Patients with T2DM (Stepwise Binary Logistic Regression Model)}

To determine the independent predictors of the prevalence of MetS a forward stepwise binary logistic regression was performed and shown in Table 6 to test 6 predictor variables: fasting blood glucose, systolic and diastolic blood pressure, waist circumference, triglyceride, HDL-cholesterol. We used NCEP-ATPIII criteria for the diagnosis of MetS. This is the only criterion definition that reflects equal importance to the every variable and showed a good agreement between the different criteria used. The dependent variable was the MetS (present, absent). A total of 700 type 2 diabetic subjects were recruited with 321 MetS and 379 were non MetS for this analysis. Higher fasting blood glucose (RP 1.008 (95\% CI: 1.005-1.011), systolic blood pressure (RP 1.047 (95\% CI: 1.034-1.060), diastolic (RP 1.059 (95\% CI: 1.035-1.083), Triglyceride (RP 1.014 (95\% CI: 1.011-1.018) low HDL-C (RP 0.969 (95\% CI: 0.960-0.979).waist circumference (RP 1.232 (95\% CI: 1.162-1.307) significantly increased the prevalence of metabolic syndrome.

Table 6. Risk factors related to prevalence of metabolic syndrome in patients with T2DM (stepwise binary logistic regression

\begin{tabular}{ll}
\cline { 2 - 2 } Variables & Odds ratio (95\% CI) \\
\cline { 2 - 3 } Fasting blood glucose $(\mathrm{mg} / \mathrm{dL})$ & $1.008(95 \%$ CI: $1.005-1.011) * *$ \\
Systolic BP (mmHg) & $1.047(95 \%$ CI: $1.034-1.060) * *$ \\
Diastolic BP (mmHg) & $1.059(95 \%$ CI: $1.035-1.083) * *$ \\
Triglyceride (mg/dL) & $1.014(95 \%$ CI: $1.011-1.018) * *$ \\
HDL-C (mg/dL) & $0.969(95 \%$ CI: $0.960-0.979) * *$ \\
Waist Circumference (Inches) & $1.232(95 \%$ CI: $1.162-1.307) * *$ \\
\hline
\end{tabular}

$* P<.05, * * P<.001$.

Our study assessed that the prevalence of MetS was highest by using IDF definition. Taking this result into account we tabulated the prevalence of individual component of MetS that could elucidate the higher influence on Indian population which may be targeted for reducing the prevalence rate. Table 7 showed the prevalence of 
metabolic syndrome by IDF definition $(\mathrm{n}=404)$ in which 266 males and 138 females. $83 \%$ of males and $94 \%$ of the females' subjects had high waist circumference. The prevalence of blood pressure in metabolic syndrome subjects is $69 \%$ in which $75.5 \%$ of males and $57 \%$ of female's subjects had high blood pressure as defined by IDF. The overall percentage of high triglyceride and low high density lipoprotein in metabolic syndrome subjects was $44 \%$ and $59 \%$ respectively. In male it was $44 \%$ and $56 \%$ but in female it was $45 \%$ and $66 \%$ respectively.

Table 7. Frequency of waist circumference, high blood pressure, elevated triglyceride, low HDL cholesterol in metabolic syndrome subjects diagnosed by IDF Criteria $(n=404)$ out of 700 type 2 diabetic subject.

\begin{tabular}{llll}
\hline Characteristics & & Male & Female \\
\hline Metabolic syndrome & 404 & 266 & 138 \\
Waist circumference(Inches) & $351(87 \%)$ & $221(83 \%)$ & $130(94 \%)$ \\
Blood Pressure(mmHg) & $280(69 \%)$ & $201(75.5 \%)$ & $79(57 \%)$ \\
High Triglyceride(mg/dl) & $179(44 \%)$ & $117(44 \%)$ & $62(45 \%)$ \\
Low HDL-C(mg/dl) & $239(59 \%)$ & $148(56 \%)$ & $91(66 \%)$ \\
\hline
\end{tabular}

\section{Discussion}

In this study we assessed the prevalence of MetS in an urban central Indian diabetic population using the World Health Organization (WHO), National Cholesterol Education Program-Adult Treatment Panel-III (NCEPATPIII) and International Diabetes Federation (IDF) criteria simultaneously and in order to assess the true defining MetS criteria by using the Agreement analysis in central Indian type 2 diabetic populations. The study also confers the ability to identify cardiovascular risk factors in terms of Metabolic and non metabolic syndrome group of subject in males and females. These three definitions consist of essential components like glucose intolerance, Hypertension, obesity, and dyslipidemia however they are having different cut-off for each parameter and also exhibited different combinations in variable to diagnosing MetS. The International Diabetes Federation has recently provided a definition more applicable in view of different ethnic populations by providing a range for increased waist circumference, which was lower for certain racial groups which is the most important one for Indian populations because we have different ethnic population from other Asian country (WHO Western Pacific Regional Office, 2000).

MetS appears to be quite common in urban Indian T2DM with an estimated prevalence of $57.7 \%, 45.9 \%, 28 \%$ by IDF, NCEP-ATP III and WHO criteria (Figure 1). Since the higher and lower prevalence may be due to different cutoffs of markers of abdominal obesity and also some other variables. Kengne et al., in 2012 reported similar observation of prevalence study on MetS. This study showed higher prevalence of MetS by using IDF criteria in comparision with NCEP-ATP III criteria among type 2 diabetic sub-Saharan Africans. More than 10\% of differences have been seen in this study.

We also find the high degree of concordance between NCEP-ATPIII \& IDF criteria which could be explained by the fact that the two definitions use the same five diagnostic components and apart from WC (essential component in IDF), the remaining criteria are nearly identically defined. The prevalence of metabolic syndrome was found to be highest in age group of $50-59$ years with $38 \%, 38 \%, 40 \%$ based on criteria of ATP III, IDF and WHO as shown in Figure 2. We observed a good agreement of Kappa value between ATP III and IDF criteria (k $=0.680$ ). Ahmed at al. (2012) reported a similar trend of agreement as observed in our study. The study concluded highest Kappa value agreement between the IDF \& NCEP-ATPIII definition ( $\mathrm{k}=0.728)$

Least agreement was seen while comparing between IDF and WHO definitions $(\mathrm{k}=0.34)$. Table $3,4 \& 5$ symbolized the comparison of clinical data among two groups (Metabolic and Non Metabolic) of type 2 diabetic subjects according to different criteria used for the study.. It was quite interesting to see the significances between the two groups respective of different variable. The metabolic syndrome with type 2 diabetic subjects diagnosed by the three definitions showed a well significance except for age and glucose level in females when compared with the non metabolic ones.

The affect of independent predictors' of the prevalence of MetS a forward stepwise binary logistic regression was performed shown in the Table 6. Accurate information regarding the prevalence of MetS and associated risk factors in people with diabetes is important for the prevention or delaying of complications including macro and microvascular disease. This study elucidates clustering of cardiovascular risk factors, and their interaction between the variables in metabolic syndrome of type-2 diabetic patients in Gwalior Chambal region of Madhya 
Pradesh (India). In a developing country like India, increasing urbanization and lifestyle changes have led to an increased incidence of diabetes (Ramachandran et al., 2008). Though Limited information is available about the prevalence of the metabolic syndrome in type 2 diabetic patients in developing nations including India. Knowledge of the variables influencing the development of the syndrome may be utilized in interventions that could favorably alter its prevalence.

Consistent with prior studies in diabetic and non-diabetic populations (Ford et al., 2002; Azizi et al., 2003; Ford $\&$ Giles, 2003) the present study found similarly increasing prevalence of MetS with increasing age in a diabetic population (Data unpublished). There are several studies reporting prevalence of the MetS in this T2DM population more than double the prevalence in the general populations (Ford, 2002; Azizi et al., 2003; Bonora et al., 1998; Rantala et al., 1999; Lee et al., 2004; Jaber et al., 2004; Meigs et al., 1997; Park et al., 2003; Florez et al., 2005). It is estimated that a large majority of patients with type $2 \mathrm{DM}$ or impaired glucose tolerance have the metabolic syndrome (Isezuo et al., 2005).

In a study of heart disease among the NHANES III participants (Alexander et al., 2003) the excess prevalence of coronary heart disease attributable to MetS and/or diabetes was found to be $37.4 \%$ in the group with metabolic syndrome without diabetes and $50.3 \%$ in the group with both metabolic syndrome and diabetes. In this regard it is of particular concern that two-thirds of patients with T2DM actually met the criteria of the MetS despite being treated for diabetes, hypertension and dyslipidaemia, with most subjects satisfying the waist circumference, blood pressure and glycemic criteria. Hence it implies the importance of prevalence study in type 2 diabetic subjects.

The present study corroborates with the observations of other studies (Ashraf et al., 2006; AlSaraj et al., 2009; Titty et al., 2008; Isezuo et al., 2005). Our study based figure is lower than the values reported by the Brazilian, Chinese, Italian, British and Scandinavian studies (Bonora et al., 1998; Costa et al., 2004; Lee \& Tsai, 2002; Ilanne-Parikka et al., 2004). Surana et al., in 2008 observed the Prevalence in type 2 diabetes in Mumbai as $77.2 \%$. When compared with other studies our study showed less prevalence may be due to the unequal distribution of selected subjects and also we recruited those subjects who were in service among males and most of the females were house wives. We reported that $64.0 \%$ of the study patients had dyslipidemia by NCEP criteria (data not shown). Obesity, hypertension, and dyslipidemia were all significantly more common among women in our study (Table 7). Prevalence rates in various studies from around the world show considerable variation. The differences in diagnostic criteria for this syndrome are partially responsible for variations in the reported prevalence among different studies (Bonora et al., 1998; Rantala et al., 1999).

Our study also provides the first estimates of the prevalence of metabolic syndrome in an urban central Indian diabetic population. Our study demonstrated prevalence of metabolic syndrome was higher among women as compared to men. Osuji et al. (2012) in his study reported prevalence of MetS dominanted in female subjects as compared to male among type 2 diabetic Nigerian. Women had a higher prevalence of low HDL and central obesity. This could partially be attributed to the lower cut-off for waist circumference and higher cut-off for HDL in women as compared to men. Therefore, probably more women were classified as having central obesity or low HDL. Men were more likely to have hypertension and hypertriglyceridemia. The prevalence of waist circumference, blood pressure and low HDL-C accordingly to IDF definition for metabolic syndrome group with diabetic subjects was $87 \%, 69 \%$ and $59 \%$, (Table 7). Adults who have type 2 diabetes, the presence of metabolic syndrome is associated with a fivefold increase in CV risk independent of age, sex, smoking status, and glycated hemoglobin (HbA1c) (Bonora et al., 2004). Therefore, it is imperative that aggressive therapy be aimed at controlling hyperglycemia, dyslipidemia and hypertension. According to IDF definition hypertension was quietly higher in males as compared with female while the waist circumferences were dominated in female group. The features of MetS continue to be present in many subjects with diabetes despite treatment for elevated glucose levels and other cardiovascular risk factors. This emphasizes the need for an aggressive multifactorial intervention in the management of cardiovascular risk in subjects with T2DM (Gaede et al., 2003).

Several limitations of our study should be recognized. First, our experimental design was cross-sectional; and hence we could not predict the complications but only suggest that the best criteria suitable for the diagnosis of MetS and could be an indicator of cardiovascular risk. We have not included complete history of medicines and lifestyle in this study that could be one of the limitations in evaluating our result and its prevalence. Our study excluded serum insulin resistance and urinary albumin excretion in the respective definitions. The present analysis is limited in its ability to elucidate causal relationships between risk factors and MetS. But the newness in our study to define the MetS criteria for the type 2 diabetic belonging to the central region of India. The study clearly shows NCEP-ATPIII and IDF definition may be suitable for identifying the high risk population in diabetic subjects. This is the first study showing interaction between these definitions among type 2 diabetic 
subjects. We also recognize the WHO definition as lower and may be could not reach the appropriate level of identification. Therefore, the study recommend the IDF and NCEP-ATPIII as a best choice and also supported by previous studies. These subjects should be paid attention in term of hypertension, obesity and dyslipidemia for the risk factor for the development of CVD The annual assessment of patients with diabetes with an appropriate definition should be included in calculation of MetS score so that those who have particularly high cardiovascular risk can be targeted for especially aggressive risk factor management.

\section{Conclusion}

In conclusion, our study demonstrates that metabolic syndrome is extremely common among diabetic patients, especially by IDF criteria and the individual factors which may responsible for the development of cardiovascular complications. Therefore it is important for those caring for people with diabetes to be aware of whether their patients also meet the criteria for MetS. Overall, metabolic syndrome can serve as a simple clinical approach to identify persons for intervention to reduce both CVD and type 2 DM.

\section{Acknowledgements}

The study was supported in part by research grants from University Grants Commission, New Delhi and Biotechnology Council of Madhya Pradesh, Bhopal. We thank the diabetic patients of Gwalior region who participated in this study.

\section{References}

Ahmed, A., Khan, T. E., Yasmeen, T., Awan, S., \& Islam, N. (2012). Metabolic syndrome in type 2 diabetes: comparison of WHO, modified ATPIII \& IDF criteria. J Pak Med Assoc, 62(6), 569-74.

Alberti, K. G. M. M., \& Zimmet, P. Z. (1998). Definition, diagnosis and classification of diabetes mellitus and its complication. Part 1. Diagnosis and classification of diabetes mellitus. Provisional report of a WHO consultation. Diabet Med, $239-53$. http://dx.doi.org/10.1002/(SICI)1096-9136(199807)15:7<539::AID-DIA668>3.0.CO;2-S

Alexander, C. M., Landsman, P. B., Teutsch, S. M., \& Haffner, S. M. (2003). NCEP-Defined Metabolic Syndrome, Diabetes, and Prevalence of Coronary Heart Disease Among NHANES III Participants Age 50 Years and Older. Diabetes, 52, 1210-1214. http://dx.doi.org/10.2337/diabetes.52.5.1210

Alexander, C. M., Loansman, P. B., \& Haffner, S. M. (2002). Prevalence of metabolic syndrome and coronary heart disease using NCEP and WHO criteria. Diabetes, 51(Suppl. 2), 883.

AlSaraj, F., McDermott, J. H., Cawood, T., McAteer, S., Ali, M., Tormey, W., \& Cockburn, B. N. (2009). Prevalence of the metabolic syndrome in patients diabetes mellitus. Ir J Med Sci, 178(3), 309-313.

Ashraf, S. M. S., Ziauddin, F., \& Jahangeer, U. (2006). Metabolic syndrome in type II Diabetes mellitus. Pak J Med Sci, 22, 295-299.

Azizi, F., Salehi, P., Etemadi, A., \& Zahedi-Asl, S. (2003). Prevalence of metabolic syndrome in an urban population: Tehran Lipid and Glucose Study. Diabetes Res Clin Pract, 61, 29-37. http://dx.doi.org/10.1016/S0168-8227(03)00066-4

Bonora, E., Kiechl, S., Willeit, J., Oberhollenzer, F., Egger, G., Targher, G., Muggeo, M. (1998). Prevalence of insulin resistance in metabolic disorders: the Bruneck Study. Diabetes, 47, 1643-1649. http://dx.doi.org/10.2337/diabetes.47.10.1643

Bonora, E., Targher, G., Formentini, G., Calcaterra, F., Lombardi, S., Marini, F., ... Muggeo, M. (2004). The metabolic syndrome is an independent predictor of cardiovascular disease in type 2 diabetic subjects. Prospective data from the verona diabetes complications study. Diabet Med, 21, 52-58. http://dx.doi.org/10.1046/j.1464-5491.2003.01068.x

Chobanian, A. V., Bakris, G. L., Black, H. R., Cushman, W. C., Green, L. A., Izzo, J.L Jr., ... Roccella, E. J. (2003). Joint National Committee on Prevention, Detection, Evaluation, and Treatment of High Blood Pressure. National Heart, Lung, and Blood Institute; National High Blood Pressure Education Program Coordinating Committee. Seventh report of the Joint National Committee on Prevention, Detection, Evaluation, and Treatment of High Blood Pressure. Hypertension, 42, 1206-1256. http://dx.doi.org/10.1161/01.HYP.0000107251.49515.c2

Costa, L. A., Canani, L. H., Lisboa, H. R., Tres, G. S., \& Gross, J. L. (2004). Aggregation of features of the metabolic syndrome is associated with increased prevalence of chronic complications in type 2 diabetes. Diabet Med, 21, 252-255. http://dx.doi.org/10.1111/j.1464-5491.2004.01124.x 
Deepa, M., Farooq, S., Datta, M., Deepa, R., \& Mohan, V. (2007). Prevalence of metabolic syndrome using WHO, ATPIII and IDF definitions in Asian Indians: The Chennai Urban Rural Epidemiology Study (CURES-34). Diabetes Metab Res Rev, 23, 127-134. http://dx.doi.org/10.1002/dmrr.658

Eckel, R. H., Grundy, S. M., \& Zimmet, P. Z. (2005). The metabolic syndrome. Lancet, 365, 1415-1428. http://dx.doi.org/10.1016/S0140-6736(05)66378-7

Florez, H., Silva, E., Fernandez, V., Ryder, E., Sulbaran, T., Campos, G., ... Goldberg, R. (2005). Prevalence and risk factors associated with the metabolic syndrome and dyslipidemia in White, Black, Amerindian and Mixed Hispanics in Zulia State, Venezuela. Diabetes Res Clin Pract, 69, 63-77. http://dx.doi.org/10.1016/j.diabres.2004.11.018

Ford, E. S., \& Giles, W. H. (2003). A comparison of the prevalence of the metabolic syndrome using two proposed definitions. Diabetes Care, 26, 575-581. http://dx.doi.org/10.2337/diacare.26.3.575

Ford, E. S., Giles, W. H., \& Dietz, W. H. (2002). Prevalence of the metabolic syndrome among US adults: Findings from the 3rd national health and nutrition examination survey. $J$ Am Med Assoc, 287, 356-359. http://dx.doi.org/10.1001/jama.287.3.356

Fossati, P., \& Prencipe, L. (1982). Serum triglycerides determined colorimetrically with an enzyme that produces hydrogen peroxide. Clinical Chemistry, 28, 2077-80.

Gaede, P., Vedel, P., Larsen, N., Jensen, G. V. H., Parving, H. H., \& Pedersen, O. (2003). Multifactorial intervention and cardiovascular disease in patients with type 2 diabetes. $N$ Engl $J$ Med, 348, 383-393. http://dx.doi.org/10.1056/NEJMoa021778

Grundy, S. M., Cleeman, J. I., Daniels, S. R., Donato, K. A., Eckel, R. H., Franklin, B. A., ... Costa, F. (2005). Diagnosis and management of the metabolic syndrome: an American Heart Association/National Heart, Lung and Blood Institute Scientific Statement. Circulation, 112, 2735-52. http://dx.doi.org/10.1161/CIRCULATIONAHA.105.169404

Ilanne-Parikka, P., Eriksson, J. G., Lindstrom, J., Hamalainen, H., Keinanen-Kiukaanniemi, S., Laakso, M., \& Tuomilehto, J. (2004). Finnish Diabetes Prevention Study Group. Prevalence of the metabolic syndrome and its components: findings from a Finnish general population sample and the Diabetes Prevention Study cohort. Diabetes Care, 27, 2135-2140. http://dx.doi.org/10.2337/diacare.27.9.2135

International Diabetes Federation. (2005). The IDF consensus worldwide definition of the metabolic syndrome;Available at http://www.idf.org/webdata/docs/Met_Syn_definition

Isezuo, S. A., \& Ezunu, E. (2005). Demographic and clinical correlates of metabolic syndrome in Native African type 2 diabetic patients. $J$ Natl Med Assoc, 97, 557-563.

Jaber, L. A., Brown, M. B., Hammad, A., Zhu, Q., \& Herman, W. H. (2004). The prevalence of the metabolic syndrome among Arab Americans. Diabetes Care, 27, 234-238. http://dx.doi.org/10.2337/diacare.27.1.234

Kelliny, C., William, J., Riesen, W., Paccaud, F., \& Bovet, P. (2008). Metabolic syndrome according to different definitions in a rapidly developing country of the African region. Cardiovascular Diabetology, 7, 27. http://dx.doi.org/10.1186/1475-2840-7-27

Kengne, A. P., Limen, S. N., Sobngwi, E., Djouogo, Catherine. F. T., \& Nouedoui, C. (2012). Metabolic syndrome in type 2 diabetes: comparative prevalence according to two sets of diagnostic criteria in sub-Saharan Africans. Diabetology \& Metabolic Syndrome, 4, 22. http://dx.doi.org/10.1186/1758-5996-4-22

Lee, W. Y., Park, J. S., Noh, S. Y., Rhee, E. J., Kim, S. W., \& Zimmet, P. Z. (2004). Prevalence of the metabolic syndrome among 40,698 Korean metropolitan subjects. Diab Res Clin Pract, 65, 143-149. http://dx.doi.org/10.1016/j.diabres.2003.12.007

Lee, Y. J., \& Tsai, J. C. (2002). ACE gene insertion/deletion polymorphism associated with 1998 World Health Organization definition of metabolic syndrome in Chinese type 2 diabetic patients. Diabetes Care, 25, 1002-1008. http://dx.doi.org/10.2337/diacare.25.6.1002

Lopes-virella, M. F., Stone, P., Ellis, S., \& Colwell, J. A. (1977). Cholesterol determination in high-density lipoproteins separated by three different methods. Chemical Communications, 23, 882-3.

Meigs, J. B., D’Agostino, R. B. Sr., Wilson, P. W., Cupples, L. A., Nathan, D. M., \& Singer, E. D. (1997). Risk variable clustering in the insulin resistance syndrome. The Framingham Offspring Study. Diabetes, 46, 1594-1600. http://dx.doi.org/10.2337/diabetes.46.10.1594 
National Cholesterol Education Program (NCEP). (2001). Expert Panel on Detection, Evaluation and Treatment of High Blood Cholesterol in Adults (Adult Treatment Panel III) Executive Summary of the third report. JAMA, 285, 2486-97. http://dx.doi.org/10.1001/jama.285.19.2486

Osuji, C. U., Nzerem, B. A., Dioka, C. E., \& Onwubuya, E. I. (2012). Metabolic syndrome in newly diagnosed type 2 diabetes mellitus using NCEP-ATP III, the Nnewi experience. Niger J Clin Pract, 15, 475-80. http://dx.doi.org/10.4103/1119-3077.104530

Park, Y. W., Zhu, S., Palaniappan, L., Heshka, S., Carnethon, M. R., \& Heymsfield, S. B. (2003). The metabolic syndrome: Prevalence and associated risk factor findings in the US population from the 3rd national health and nutrition examination survey 1988-1994. Arch Int Med, 163, 427-436. http://dx.doi.org/10.1001/archinte.163.4.427

Paul, Z., \& Alberti, G. (2005). The metabolic syndrome: perhaps an etiologic mystery but far from myth — where does the International Diabetes Federation Stand? Medscape Diabet Endocr, 7(2). posted www.medscape.com

Ramachandran, A., Mary, S., Yamuna, A., Murugesan, N., \& Snehalatha, C. (2008). High prevalence of diabetes and cardiovascular risk factors associated with urbanization in India. Diabetes Care, 31, 893-98. http://dx.doi.org/10.2337/dc07-1207

Rantala, A. O., Kauma, H., Lilja, M., Savolainen, M. J., Reunanen, A., \& Kesaniemi, Y. A. (1999). Prevalence of the metabolic syndrome in drug-treated hypertensive patients and control subjects. $J$ Intern Med, 245, 163-174. http://dx.doi.org/10.1046/j.1365-2796.1999.00429.x

Reaven, G. M. (1988). Banting lecture role of insulin resistance in human disease. Diabetes, 37, 1595-607. http://dx.doi.org/10.2337/diabetes.37.12.1595

Stockbridge, H., Hardy, R. I., \& Glueck, C. J. (1989). Public cholesterol screening: Motivation for participation, follow-up outcome, self-knowledge and coronary heart disease risk factor intervention. J Lab Clin Med, 114, 142-151.

Surana, S. P., Shah, D. B., Gala, K., Susheja, S., Hoskote, S. S., Gill, N., Joshi, S. R., \& Panikar, V. (2008). Prevalence of Metabolic Syndrome in an Urban Indian Diabetic Population Using The NCEP ATP III Guidelines. JAPI, 56, 865-868.

Titty, F. V. K., Owiredu, W. K. B. A., \& Agyei, Frempong, M. T. (2008). Prevalence of MetS and its individual components among Diabetic patients in Ghana. Journal of Biological Science, 8, 1057-1061. http://dx.doi.org/10.3923/jbs.2008.1057.1061

Trinder, P. (1969). Determination of glucose in blood using glucose oxidase with an alternative oxygen acceptor. Annal. Clin. Biochem., 6, 24-27.

WHO Western Pacific Regional Office, IOTF, IASO. The Asia-Pacific perspective: Redefining obesity and its treatment.Sydney; Health Communications Australia, 2000.

Wilson, P. W., D’Agostino, R. B., Levy, D., Belanger, A. M., Silbershatz, H., \& Kannel, W. B. (1998). Prediction of coronary disease using risk factor categories. Circulation, 97, 1837-47. http://dx.doi.org/10.1161/01.CIR.97.18.1837

\section{Copyrights}

Copyright for this article is retained by the author(s), with first publication rights granted to the journal.

This is an open-access article distributed under the terms and conditions of the Creative Commons Attribution license (http://creativecommons.org/licenses/by/3.0/). 